\title{
Avaliação das características de afetividade em crianças e jovens com síndrome de Down ${ }^{1}$
}

\author{
Elaine Custódio Rodrigues² - Universidade Federal do Rio Grande do Norte, Natal, Brasil \\ João Carlos Alchieri - Universidade Federal do Rio Grande do Norte, Natal, Brasil
}

\begin{abstract}
Resumo
Este trabalho buscou investigar a manifestação da afetividade em crianças e jovens com síndrome de Down (SD) e a percepção de pais e educadores quanto à sua expressão no comportamento e nas atividades sociais. Participaram 70 pessoas com SD, na faixa etária de 4 a 26 anos. Os instrumentos utilizados foram questionários sobre percepção da afetividade, aplicados aos pais e professores, e o Zulliger, avaliando os indivíduos com SD. Os dados dos questionários foram analisados pelo programa Tri-deux-Mots, e o Zulliger foi avaliado buscando caracterizar os aspectos da afetividade, com base no método de Klopfer. Pelo Tri-deux-mots, observou-se que tanto no comportamento afetivo como no relacionamento com o outro os sujeitos com SD expressam sua afetividade mediante características positivas e negativas. O Zulliger possibilitou elementos iniciais, no entanto é preciso estudos futuros para investigar o motivo das respostas não estarem direcionadas às categorias relacionadas à afetividade.

Palavras-chave: afetividade; síndrome de Down; zulliger.
\end{abstract}

\section{Assessment of characteristics of affectivitty among individuals with Down syndrome}

\begin{abstract}
This work intended to investigate the expression of the affectivity among children and young people with down syndrome and also the perception that parents and educators have of this expression in the behaviour and social activities. Seventy people with down syndrome took part in the research, in the age group from 04 to 26 years old. In terms of the instruments, questionnaires concerning the perception of the affectivity were applied to parents and teachers, and the Zulliger was used to assess the individuals with down syndrome. The data from the questionnaires were analyzed by the program Tri-deux-Mots, and the Zulliger, based on the method of Klopfer, was evaluated with the intention of describing the aspects of the affectivity. By the use of the Tri-deux-Mots, it was noticed that, both in the affectional behaviour and the relationship with the other, the subjects with Down Syndrome express their affectivity through positive and negative characteristics. The Zulliger created the possibility of some elements, however future studies are needed in order to investigate the reason why the answers are not directed to the categories concerning the affectivity.

Keywords: affectivity; down Syndrome; zulliger Test.
\end{abstract}

\section{Introdução}

Este trabalho apresenta os processos e os resultados de uma pesquisa acerca da afetividade em crianças e jovens com síndrome de Down (SD). A relevância do estudo justifica-se pela necessidade do desenvolvimento de pesquisas, na área de avaliação psicológica de pessoas com síndrome de Down (SD), que sejam respaldadas mediante a utilização de instrumentos apropriados para tal finalidade (Pawlowski, Bandeira \& Severo, 2004).

A psicologia no Brasil enfrenta dificuldades no tocante ao desconhecimento de

\footnotetext{
1 Esse artigo foi extraído da dissertação de mestrado intitulada Avaliação das características de afetividade em crianças e jovens com síndrome de Down, aprovada pela Universidade Federal do Rio Grande do Norte. Apoio: CAPES

${ }^{2}$ Endereço para correspondência:

Rua João Sérgio de Almeida, 489, Bairro Bocongó. Campina Grande, PB. CEP 58430-340.

E-mail: lainecr.psi@hotmail.com
}

informações sobre a fidedignidade, validade e padronização de instrumentos psicológicos vindos do exterior, assim como se defronta com o enigma de estabelecer normas específicas para testes elaborados num país culturalmente diversificado (Alchieri, Aquino, Martins, Oliveira \& Gonçalves, 2006). Nesse sentido, torna-se imprescindível elaborar um estudo com pessoas com SD, em virtude dos problemas e limitações em relação à pouca expressão deste tema no Brasil.

Considerando, particularmente, a importância desse desafio, o objetivo geral da presente pesquisa consiste em investigar características de afetividade nas crianças e jovens com SD, bem como a percepção de pais e educadores quanto à expressão dessa afetividade no comportamento e nas atividades sociais. Quanto aos objetivos específicos, buscou-se: identificar percepções dos pais sobre as diversas manifestações de comportamentos indicativos de afetividade; verificar, no ambiente social extradomicílio, mediante a percepção dos professores, as diversas formas e intensidades da expressão da 
afetividade; e possibilitar o uso e estudo da técnica de Zulliger (Z-Teste), em pessoas com SD.

Além disso, a escolha pela temática estudada se deu em razão de inquietações profissionais acerca do que as pessoas pensam sobre o comportamento das crianças com SD, pois é comum observar comentários de que essas crianças possuem uma afetividade exagerada, por causa da síndrome. Diante disso, a expressão da afetividade das crianças e jovens com SD configura-se como objeto do presente estudo. Para apreendê-lo, buscou-se saber como os pais e os professores observam as características de afetividade desses indivíduos e, por meio do ZTeste, a forma pela qual as crianças e jovens expressam e manifestam a afetividade (Rodrigues, 2008).

Conhecer os passos relativos ao desenvolvimento da afetividade é de extrema importância para a compreensão do comportamento de crianças com SD. Pinto (2004) mostra que é fundamental visualizar o conceito acerca da afetividade "como um dos conteúdos psicológicos que exercem um papel imprescindível na organização e no funcionamento psíquico no ser humano". Doron e Parot (2001, p. 35) declaram que a afetividade constitui "noção de extensão e compreensão bastante vagas, que engloba estados tão diversos como as emoções, as paixões, os sentimentos, a ansiedade, a angústia, a tristeza, a alegria, mesmo as sensações de prazer e dor".

A escolha da técnica de Zulliger, portanto, justifica-se pelo fato de o mencionado teste averiguar a personalidade do examinando, pois pela percepção da pessoa é possível estudar sua estrutura mental e, por conseguinte, os seus aspectos afetivos. Afinal, de acordo com Vaz (2000), as respostas verbalizadas durante a aplicação do Zulliger significam toda a produção da pessoa durante o teste, expressando sua capacidade de adaptação e produção na realização $\mathrm{da}$ atividade. Nas respostas, encontra-se o resultado de uma atividade constituída de dificuldades, que a pessoa precisou enfrentar e resolver, utilizando o seu grau de inteligência, assim como as condições específicas da sua personalidade.

Para Martins (2002, p. 55), muitos questionamentos foram feitos acerca da personalidade da pessoa com SD e a respectiva influência da genética sobre a mesma. Há crenças que buscam caracterizar o comportamento dos indivíduos com $\mathrm{SD}$, passando a idéia de que estes são afetuosos, dóceis, calmos, brincalhões, bons imitadores e apreciadores da música, criando-se um estereótipo que não corresponde à realidade, tendo em vista que são distintos em relação à personalidade e ao temperamento, como qualquer outra pessoa.

Como expressa Schwartzman (2003): ... não há um padrão estereotipado e previsivel em todas as crianças afetadas, uma vez que tanto $o$ comportamento quanto 0 desenvolvimento da inteligência não dependem exclusivamente da alteração cromossômica, mas também do restante do potencial genético bem como das importantissimas influências derivadas do meio (p.58).

Autores como McConnaughey e Quinn (2007) salientam que o desenvolvimento humano constitui um processo complexo pelo qual a criança, à medida que vai crescendo, adquire habilidades. Cada indivíduo possui sua unicidade e se desenvolve mediante uma interação complexa entre os fatores biológicos/genéticos, psicológicos, culturais e ambientais, incluindo também as expectativas que surgem em relação às potencialidades, capacidades e aos aspectos afetivo-emocionais relacionados à aprendizagem das coisas do mundo (Bissoto, 2005; Lamônica, Vitto, Garcia \& Campos, 2005). É importante acrescentar, portanto, que os aspectos afetivos estão sob efeito de diversas condições e influências positivas e negativas, como serão observadas no decorrer do artigo.

\section{Método}

Os diversos aspectos do fenômeno psicológico investigado foram contemplados nas dimensões qualitativa e quantitativa. Assim sendo, valorizou-se a obtenção de elementos que pudessem identificar e caracterizar os aspectos do comportamento de crianças e jovens, na resposta ao Z-teste e na percepção de seus pais e professores. Trata-se de um estudo observacional, cuja variável principal é a expressão da afetividade. Os dados da pesquisa foram obtidos com o auxílio da observação sistemática, a qual, como define Marconi e Lakatos (2003, p. 193), "realiza-se em condições controladas, para responder a propósitos preestabelecidos". As observações efetuadas foram planejadas e sistematizadas, e a pesquisadora detinha controle sobre o que procurava e o que carecia de importância nas situações da pesquisa. 
Participaram da pesquisa setenta crianças e jovens com síndrome de Down, na faixa etária de quatro (4) a vinte e seis (26) anos, sendo trinta e sete (37) do sexo feminino e trinta e três (33) do sexo masculino, assistidos, junto a diversas instituições da Paraíba e do Rio Grande do Norte. As instituições e as cidades abarcadas foram: Associação de Pais e Amigos dos Excepcionais (APAE - Campina Grande-PB, Patos-PB, Esperança-PB e Natal-RN), Instituto Campinense de Assistência ao Excepcional (ICAE - Campina Grande-PB), Associação Viva Down (Campina Grande-PB) e uma escola regular da rede particular de ensino de Campina Grande-PB, a qual solicitou sigilo quanto a sua identificação institucional.

Como instrumentos para a coleta, utilizaram-se questionários e uma técnica projetiva, Z-teste, aplicada individualmente. Os questionários foram aplicados com os pais e professores, tendo objetivo de avaliar a expressão da afetividade das crianças e dos jovens nos ambientes residenciais e escolares.

O questionário de avaliação das atividades no meio intrafamiliar constou de dez (10) questões sobre o comportamento e a expressão de afetividade no domićlio e foi preenchido pelos pais ou responsáveis. O questionário de atividades escolares, com seis (6) questões, procurou verificar o comportamento $\mathrm{e}$ as diversas expressões da afetividade no ambiente escolar, e foi preenchido pelos professores responsáveis pelos alunos.

A técnica foi o Z-Teste, baseada nas técnicas de manchas de tinta, como o Rorschach, cujo objetivo é investigar a dinâmica da personalidade. O Zulliger é composto por três lâminas na versão individual e slides na coletiva, folhas de localização e folhas de síntese. A aplicação foi realizada de forma individual com base nos requisitos técnicos propostos, para o Brasil, por Vaz (2002). Os cuidados mais específicos adotados foram: o uso em recinto confortável, com luminosidade natural; mesa de aproximadamente $2,0 \mathrm{~m} \times 1,5 \mathrm{~m}$; duas cadeiras $\mathrm{e}$ mesinha pequena para os cartões; folhas de papel almaço; folha para mapeamento das respostas ou folhas de localizações das respostas do Z-Teste; caneta ou lápis e relógio. Como aspecto diferenciado da técnica, foi adotada a tomada de tempo nas aplicações individuais, visando à obtenção de tempos de reação e duração, enquanto variáveis para a verificação do processo de adaptação dos participantes.
Foram aplicados sessenta e nove questionários com os pais, pois um dos pais da escola regular não respondeu, mas autorizou seu filho a participar da pesquisa. Em relação aos professores, foram aplicados cinquenta e um questionários, entregues em sala de aula para que eles pudessem responder e entregar em seguida. Com exceção de alguns, os professores se mostraram disponíveis e entregaram os questionários no prazo estabelecido. Por outro lado, não foi possível aplicar com todos os professores, pois algumas crianças e jovens se encontravam apenas em atendimentos clínicos. É importante mencionar que a maioria das instituições pesquisadas são escola/clínica, logo, o contato com as crianças e jovens e para aplicação do teste foi realizado na sala de aula, quando matriculados na escolaridade, e diretamente com os outros profissionais (fonoaudiólogos, fisioterapeutas, terapeutas ocupacionais e psicólogos), quando eram atendidos na clínica. Para aplicação do teste, eram dadas as seguintes instruções: Nós vamos faz̧er uma atividade bem diferente hoje, em que eu vou lhe mostrar uns cartões/figuras e você vai me dizer o que vê neles, com que parece. Enquanto você fala dos três cartôes, irei anotar tudo e depois nós vamos conversar sobre o que você viu. Entendeu? Não apresentando dúvidas, iniciava-se a aplicação do Zulliger.

É fundamental acrescentar que a aplicação foi um pouco diferenciada das exigências preconizadas, pois quando se entregava a lâmina, muitas vezes era imprescindível interagir com os examinandos, ou seja, era preciso reforçar constantemente sua colaboração e motivação indagando: o que você está vendo? Com que parece? Além disso, muitas vezes eles terminavam e não entregavam a lâmina e por isso era necessário perguntar: Você já terminou? Esse fato demonstra ainda mais a importância da sistematização e padronização para as necessidades específicas dessas pessoas.

Para analisar os dados dos questionários utilizou-se o programa Tri-deux-mots, empregado para analisar questões abertas, fechadas e/ou associação de palavras (Coutinho, 2005). Para a análise dos dados do Z-Teste levou-se em consideração a necessidade de caracterizar os aspectos da afetividade em crianças e jovens e a elaboração de normas específicas para esse tipo de amostra, por meio de escores normalizados. As respostas dadas pelos respondentes no Zulliger foram classificadas com base no sistema de Klopfer (Vaz, 2002) e tabuladas em planilhas 
eletrônicas, conforme classificação corrente. Cabe ressaltar que as classificações das diversas respostas foram verificadas por meio de juízes, psicólogos e docentes experientes na técnica, de forma a evitar discrepâncias. Realizada a verificação, foi adotada a avaliação de Kappa para estimar a concordância entre juízes. Como variáveis-alvos têm-se: DG elaborada, F+\%, FC, $\mathrm{CF}, \mathrm{C}, \mathrm{M}+, \mathrm{M}+\%, \quad \mathrm{H}$ e $\mathrm{Hd}$, presença de indicadores de comprometimento (choques ou para-respostas), juntamente com análises combinadas das varáveis descritas. Após as respostas serem planilhadas, foi realizada a análise estatística descritiva e inferencial, a fim de verificar possíveis distinções entre os dados sociodemográficos. Com esse objetivo, através do programa SPSSWIN 15 (Statistical Package for the Social Science 15,0), foram efetuadas análises de variância ANOVA com o intuito de comparar as médias das respostas do Z-Teste com as variáveis sexo e faixa etária.

\section{Resultados dos questionários processados pelo Tri-deux-mots}

Com o objetivo de se utilizar o software Trideux-mots e, por meio deste, realizar a análise fatorial de correspondência (AFC), foi organizado um dicionário de palavras, relacionadas às expressões de estímulos indutores, organizadas por ordem alfabética. Em seguida, foi organizado um banco de dados contendo as variáveis fixas e as variáveis de opinião (estímulos indutores) constituídas de acordo com os objetivos específicos da pesquisa. As variáveis fixas foram representadas pelos participantes (pais ou responsáveis e professores), pelo sexo (masculino e feminino) e pela idade (20 a 51 anos). Os estímulos indutores corresponderam às respostas dos pais/responsáveis ou professores acerca da afetividade das crianças com síndrome de Down, em casa e na sala de aula, os quais foram denominados como: o comportamento afetivo e o relacionamento com o outro. Ao analisar os dados desta pesquisa, foi possível realizar a análise fatorial de correspondência das respostas dos pais e professores aos dois estímulos indutores com as maiores cargas fatoriais associadas às variáveis fixas (participantes, sexo e idade). Registraram-se 1.000 palavras como respostas aos dois estímulos indutores, das quais 712 foram diferentes, reduzidas de acordo com a ligação dos termos com a semelhança das translações sofridas pela significação das palavras, estabelecida pelo próprio programa. Esta redução, pela similaridade semântica destas palavras diferentes, revelou mediante o programa computacional, que 56 palavras fizeram parte do plano fatorial, de acordo com a contribuição referente a cada palavra para o espaço fatorial determinado. A média da carga fatorial dessas palavras equivale a 17,85. Para calcular essa média, leva-se em consideração a soma das cargas fatoriais (1.000) e divide-se pelo total de palavras (56).

Nessa etapa do processamento e análise dos dados, tem-se o intuito de apreender as palavras relacionadas ao comportamento e relacionamento afetivo das crianças com síndrome de Down. Para isso é necessário calcular o dobro da média das cargas fatoriais $(17,85 \times 2=35,7)$ e então identificar as palavras que tiveram um maior significado na construção dos fatores do plano fatorial. Tais palavras serão apresentadas, com suas respectivas médias, nos parágrafos abaixo, de acordo com os estímulos indutores.

Por meio das maiores contribuições fatoriais processadas pelo Tri-deux-mots, percebe-se que o comportamento afetivo das crianças com SD apresentado pelos pais é classificado como: agressivo (38), carinhoso (43), não-agressivo (53) e ótimo (39). Já para os professores, os alunos em sala de aula demonstram um comportamento amoroso (36), compreensivo (39), tranquilo (71), triste (70) e variável/inconstante (110), sendo que os valores mais expressivos encontram-se entre apresentar um comportamento não-agressivo, triste, tranquilo e inconstante.

Tendo como base o estímulo indutor "relacionamento com o outro", percebe-se que a palavra com maior carga fatorial revelada pelos pais indica que as crianças e jovens com SD, no relacionamento com o outro, são muito carinhosas (93). Os pais também afirmam que elas são alegres (39), têm um bom relacionamento (42), gostam de brincar ou são brincalhonas (43), demonstrando confiança (35), respeito (46) e felicidade (48). Já os professores enfatizam que estas crianças são muito apegadas (63) às suas amizades, assim como são ciumentas (35), confiantes (47), apresentando um relacionamento muito bom (36) em sala de aula.

Nesse sentido, percebe-se que, para cada estímulo indutor, surgiram palavras que apresentam maiores cargas fatoriais, e estas estão relacionadas a cada um dos fatores processados pelo programa. 


\section{Resultados da técnica do Zulliger}

Os participantes submetidos à técnica do Zulliger encontram-se nas faixas etárias de 4 a 11 , $(41,4 \%), 12$ a $19(51,4 \%)$ e de 20 anos ou mais $(7,1 \%)$, perfazendo uma idade média de 12,3 , com 4,3 de desvio padrão; sendo $52,9 \%$ do sexo feminino, $30 \%$ matriculados na pré-escola, 55,7\% na alfabetização, 7,1\% encontrando-se na primeira, segunda e quarta série e 7,1\% em outras atividades. Apesar de alguns estarem em níveis de escolaridades mais avançados, é importante ressaltar que, da mesma forma que os outros, ainda não possuem o domínio da leitura e da escrita com desenvoltura. Considerando os tempos de reação e duração, foram organizadas médias e desvio padrão para as variáveis sexo e faixa etária, com o intuito de verificar os valores significativos que destacam o tempo em que cada indivíduo levou para dar a primeira resposta, e o tempo em que ele permaneceu com cada lâmina, até sua entrega.

Para verificar a presença de diferenças significativas em relação aos tempos de reação e duração e às variáveis sexo e faixa etária, utilizou-se a Análise de Variância Univariada (ANOVA). Observando a Tabela 1, nota-se que há apenas um único destaque estatisticamente significativo, o qual está presente na variável sexo, no tempo de duração da lâmina III $[\mathrm{F}(4,716)=0,033 ; \quad p<0,05], \quad$ demonstrando que as crianças e jovens do sexo feminino $(52,9 \%)$ permaneceram com a lâmina em uma média de 53,3s.

Tabela 1. Análises univariadas dos tempos de reação e duração do Z-Teste de acordo com o sexo e a faixa etária

\begin{tabular}{ccccccc}
\hline & \multicolumn{7}{c}{ ANOVA } & & \\
\hline LIII & TR LI & TR LII & TR LIII & TD LI & TD LII & TD \\
\hline Variáveis & & & & & & \\
Sexo (S) & 0,021 & 0,533 & 0,842 & 0,057 & 1,279 & $4,716^{*}$ \\
Idade (I) & 1,903 & 0,259 & 0,096 & 1,045 & 1,114 & 0,873 \\
\hline
\end{tabular}

Notas: ANOVA=análise de variância univariada; ${ }^{*} p<0,05$; Notas: TR: Tempo de Reação Lâminas I, II, III TD: Tempo de Duração Lâminas I, II, III.

Em relação aos determinantes do movimento humano (M) observou-se que nenhum participante apresentou respostas de $\mathrm{M}+$, somente um $(1,4 \%)$ apresentou uma resposta equivalente a $\mathrm{M}+-$, seis $(8,6 \%)$ apresentaram uma respostas referente a $\mathrm{M}$ - e três $(4,3 \%)$ participantes duas, em relação à mesma variável. Assim, foi observado um total (TM) de quatro respostas nesse determinante, que equivale a $14,3 \%$ dos participantes. Na Tabela 2 , em relação à faixa etária, encontra-se um dado significativo no determinante $\mathrm{M}-[\mathrm{F}(3,070)=0,053$; $p<0,05]$.

Tabela 02. Análises univariadas dos determinantes M+- e M- de acordo com o sexo e a faixa etária

\begin{tabular}{|c|c|c|c|c|}
\hline \multicolumn{5}{|c|}{ ANOVA } \\
\hline & \multicolumn{2}{|c|}{$\mathrm{M}+-$} & \multicolumn{2}{|c|}{ M- } \\
\hline & $\mathrm{F}$ & $\mathrm{P}$ & $\mathrm{F}$ & $\mathrm{P}$ \\
\hline \multicolumn{5}{|l|}{ Variáveis } \\
\hline $\operatorname{Sexo}(\mathrm{S})$ & 0,890 & 0,349 & 1,369 & 0,246 \\
\hline Idade (I) & 0,465 & 0,630 & 3,070 & $0,053^{*}$ \\
\hline
\end{tabular}

Notas: $A N O V A=$ análise de variância univariada; ${ }^{*} p<0,05 ; M+-=$ movimento bumano duvidoso, $M-=$ movimento bumano de má performance.

Em se tratando dos conteúdos abstratos (Abstr.), verificaram-se duas respostas, representando $2,9 \%$ da amostra. Nos conteúdos geográficos, foram observadas uma resposta nos $5,7 \%$ dos casos e duas respostas em 1,4\%. Analisando esses dados pela ANOVA, na Tabela 3 observa-se que há destaque em duas médias, ambas relacionadas à variável idade no conteúdo abstrato (Abst.) $[\mathrm{F}(3,225)=0,046 ; p<0,05] \quad$ e geográfico (Geog.) $[\mathrm{F}(3,621)=0,032 ; p<0,05]$.
Vale ressaltar que os resultados apresentados destacam apenas os dados considerados significativos, pois nas outras variáveis não foram verificadas diferenças significativas nas médias.

\section{Discussão}

Em consonância com os autores McConnaughey e Quinn (2007), Lamônica, Vitto, Garcia e Campos (2005) e Bissoto (2005), é 
importante levar em consideração que o desenvolvimento da criança com SD é um processo complexo como o de qualquer outra criança, ou seja, ao longo dos anos, ela vai adquirindo habilidades específicas de acordo com o estímulo que recebe. Isso indica que, embora os indivíduos com SD apresentem características fenotípicas compatíveis à síndrome, não quer dizer que exista somente uma única maneira de agirem, ou que tenham o mesmo comportamento. Por isso, discutir a afetividade dessas crianças e jovens implica considerar os aspectos envolvidos na comunicação enquanto elementos imprescindíveis para a organização e o funcionamento psíquico do ser humano, que conceitualmente carrega, em si, emoções, paixões, sentimentos, ansiedades, angústias, alegrias, tristezas (Pinto, 2004; Doron \& Parot, 2001).

Tabela 3. Análises univariadas dos conteúdos Abst., Anat., Bot., Obj., e Geog. de acordo com o sexo e a faixa etária

\begin{tabular}{|c|c|c|c|c|c|c|c|c|c|c|}
\hline \multicolumn{11}{|c|}{ ANOVA } \\
\hline & \multicolumn{2}{|c|}{ Abst. } & \multicolumn{2}{|c|}{ Anat. } & \multicolumn{2}{|c|}{ Bot. } & \multicolumn{2}{|c|}{ Obj. } & \multicolumn{2}{|c|}{ Geog. } \\
\hline & $\mathrm{F}$ & $p$ & $\mathrm{~F}$ & $\mathrm{p}$ & $\mathrm{F}$ & $p$ & $\mathrm{~F}$ & $p$ & $\mathrm{~F}$ & $p$ \\
\hline Variáveis & & & & & & & & & & \\
\hline Sexo $(S)$ & 2,319 & 0,132 & 0,002 & 0,967 & 0,033 & 0,857 & 1,598 & 0,210 & 0,359 & 0,551 \\
\hline Idade (I) & 3,225 & $0,046^{*}$ & 0,724 & 0,489 & 0,564 & 0,571 & 0,532 & 0,590 & 3,621 & $0,032 *$ \\
\hline
\end{tabular}

De acordo com os resultados, percebe-se que os pais e professores externaram como as crianças e jovens com síndrome de Down se comportam afetivamente e como se dá a relação com o outro. Levando em consideração a opinião dos professores, em geral, na escola, algumas crianças e jovens com SD demonstram um relacionamento "tranquilo", "atencioso" e "obediente" em relação a eles e aos colegas, mas outros apresentam agressividade em relação ao comportamento afetivo em sala de aula. Contudo, os professores na faixa etária 20-30 afirmam que o comportamento afetivo da maioria "não é agressivo", pois são "pessoas tranquilas", "muito prestativas", apesar de às vezes serem "teimosas". $\mathrm{Na}$ relação com o outro, possuem um "ótimo comportamento", demonstrando "alegria ou felicidade", "carinho" e "respeito" nas suas ações. Uma outra opinião dos professores salienta que, no tocante ao estímulo indutor "comportamento afetivo", os alunos apresentam características como "variável" e "inconstante". No que diz respeito ao estímulo "relacionamento com o outro", que envolve os professores e os colegas, o relacionamento é "muito bom" e demonstra "confiança". Os professores da faixa etária entre 20-30 anos reforçam que o relacionamento com o outro é "bom" e que são pessoas muito "amigáveis". Percebe-se, então que há respostas divergentes entre os professores, em relação ao comportamento afetivo, pois alguns revelam que os alunos em sua maioria, "não são agressivos" e que apesar de serem "teimosos" são "tranquilos" e “prestativos". Já outros professores dizem que eles possuem um comportamento "variável" e "inconstante" (Rodrigues, 2008).

As palavras destacadas pelos pais de 31-40 anos afirmam que as crianças e jovens em casa são muito "amorosas" e "carinhosas" e, na relação com o outro, gostam de "conversar", "brincar" e algumas demonstram ser "brincalhonas". Já os pais com mais de 51 anos dão ênfase apenas à palavra "amoroso" para identificar o comportamento afetivo das crianças e jovens em casa. Uma outra opinião dos pais, na faixa etária entre 31-40 e mais de 51 anos, revela que as crianças e jovens possuem um "comportamento normal". Sendo que os pais de 31-40 anos acrescentam que as crianças e jovens algumas vezes são "tranquilos" e "meigos", mas às vezes demonstram "raiva". Da mesma maneira, os pais com mais de 51 anos afirmam que seus filhos, em relação ao comportamento afetivo, são "compreensivos" e "atenciosos"; no entanto, em alguns momentos, demonstram-se "aborrecidos", "tristes" e "irritados". Já na relação com o outro são definidos como muito "apegados" à família e aos amigos, sendo pessoas "contentes", mas também são "arengueiros" e "ciumentos". Observa-se que na primeira opinião dos pais, são destacadas apenas palavras positivas para exemplificar o comportamento dos seus filhos, enquanto logo após, os pais de 31-40 e mais de 51 anos dizem que seus filhos possuem um comportamento "normal", no entanto, em certos momentos apresentam-se "aborrecidos", com "raiva", "tristes" e "irritados", e às vezes “arengueiros" e ciumentos" (Rodrigues, 2008). 
Como afirma Martins (2002), existem ideias pré-concebidas que buscam caracterizar o comportamento desses indivíduos com SD, idealizando-os como afetuosos, dóceis, calmos, brincalhões etc., originando um estereótipo que, como se vê, não é compatível com o real, pois eles são únicos e apresentam diferenças em relação à personalidade e temperamento como qualquer outro indivíduo.

Nesse sentido, os autores Martins (2002), Schwartzman (2003) e Rodríguez (2004) enfatizam que a criança com SD apresenta comportamentos semelhantes aos de uma criança que não possui a síndrome, na mesma faixa etária, ou seja, sua vida emocional é tão rica como a de qualquer outra pessoa. Por isso, não há possibilidade de existir um padrão estereotipado e/ou único para todas as crianças com SD, pois, além da alteração cromossômica, encontram-se as importantes influências advindas do meio. Os problemas emocionais e de conduta estão, na maioria das vezes, ligados aos fatores ambientais e familiares, ou seja, com a forma com que os pais lidam e tratam seus filhos.

Como afirma Silva e Dessen (2006), a relação entre a família e a criança é de fundamental importância, afinal, a forma como essa criança é inserida no grupo familiar pode afetar completamente o seu desenvolvimento. É importante ressaltar a linha de raciocínio proposta por Ying-Li, Ming Liu, Yan Lok e Kwan Lee (2006), segundo a qual o apoio familiar e o cultivo entre os pais de uma percepção positiva da síndrome são elementos fundamentais no processo que envolve conquistas profissionais. Afirmam os autores:

Our findings suggest that the positive personality of and role modeling by their parents were the two important factors that contribute to the participants' achievement in life. Based on findings of this present study, quality family support and counseling should be further developed to support parents to facilitate their children with intellectual disabilities to achieve self development. It is also important to have ongoing collaboration among family, school and community facilities so that people with intellectual disabilities are supported to develop their potential and coping strategies for a higher level of social integration (p.152).

Por esse motivo, destaca-se que a afetividade exerce uma função imprescindível no entendimento e na compreensão das relações interpessoais. A criança com SD apresenta dificuldade em se comunicar com os outros e provavelmente essa limitação pode prejudicar suas relações afetivas, por ela não conseguir exteriorizar e compreender, de forma clara, sua vinculação social (Rodríguez, 2004). Essa dificuldade na comunicação foi observada na aplicação do Zulliger.

A possibilidade do estudo de elementos para a indicação e utilização da técnica de Zulliger, em pessoas com síndrome de Down, através da elaboração de indicadores e normas regionalizadas, não foi identificada nos estudos atuais. Optou-se por que ao entregar as lâminas aos sujeitos da pesquisa, os tempos de reação e duração fossem controlados e identificados. O tempo de reação caracteriza-se pelo momento em que o indivíduo recebe a lâmina e dá a primeira resposta, enquanto o tempo de duração seria o momento em que o indivíduo recebe a lâmina até a sua entrega. Dando ênfase ao tempo de reação, verificou-se, no decorrer da aplicação do teste, uma diminuição na variação do tempo, já que, na primeira lâmina, foi destacado de $5 \mathrm{~s}$ a $214 \mathrm{~s}$ para se dar a primeira resposta, na segunda lâmina de $1 \mathrm{~s}$ a $103 \mathrm{~s}$ e na terceira lâmina 2 s a 59 s. Isso pode indicar que, à medida que as crianças e jovens iam tendo acesso a sequência das lâminas, se tornava mais fácil apresentarem as respostas com mais rapidez e revelava não somente a capacidade de produção, mas de relação estabelecida com a examinadora.

No tempo de duração na primeira lâmina cuja variação ficou entre 13 s e 247 s, e na segunda, $8 \mathrm{~s}$ a $154 \mathrm{~s}$, percebeu-se também uma variação menor dos tempos, o que pode indicar adaptação e agilidade. No entanto, na lâmina três (8s a 227s) ocorre um aumento na amplitude. Por vários motivos, apenas cinco crianças não conseguiram responder as solicitações da examinadora. Algumas tinham dificuldade na fala e não era possível entender o que expressavam, outras ficaram muito inquietas e não conseguiram se concentrar e outra se comunicava com gestos e parecia comparar as lâminas com alguma parte do seu corpo. Vale ressaltar que essas crianças, na verdade, expressaram-se diante das lâminas, como se entendessem as solicitações, porém pelas dificuldades, principalmente da comunicação, não foi possível compreendê-las.

Sabe-se que o total de respostas representa a construção do trabalho da pessoa diante da técnica, podendo ser caracterizada quanto a sua capacidade de apropriação da atividade, assim como sua produção, desempenho e realização. Além disso, o somatório das respostas simboliza 
uma tarefa composta de dificuldades que a pessoa necessita enfrentar e resolver, utilizando a inteligência e sua condição pessoal (Vaz, 2002). Segundo o autor, esses aspectos podem influenciar no total de respostas. Por sua vez, tanto as respostas compreensíveis como as de difícil compreensão (pela fala) foram expostas, pelas crianças e jovens com SD, dentro das suas condições, demonstrando condições cognitivoafetivas de construir um significado próprio.

As localizações, ou seja, as áreas em que os indivíduos localizam a resposta representam, de um modo geral, a maneira como ele percebe racionalmente a realidade e a forma como utiliza as suas condições cognitivas e perceptivas para fornecer uma resposta. Vaz (2000) explica que, em relação à deficiência mental, os examinandos possuem dificuldades de organizar o pensamento diante das manchas, gerando um processo de repetição, perseverando na apresentação de globais com o mesmo conteúdo. Por sua vez, ao verificar as respostas exibidas pelas crianças e jovens com $\mathrm{SD}$, percebeu-se que quase todas estavam relacionadas, especificamente, à palavra "bicho" e "animal" ("aranha", "sapo", "leão", "cachorro", "macaco", "formiga" etc.), o que pode caracterizar um quadro de perseveração ou ainda de limitação dos interesses das crianças.

Entende-se que as respostas globais $(G)$ indicam o conjunto perceptivo do indivíduo e o seu senso de organização. A maioria $(84,3 \%)$ dos participantes deu respostas referentes a essa localização. A categoria dos detalhes comuns (D) representa a maneira como os indivíduos percebem o mundo, os objetos e as pessoas diante da realidade, ou seja, significam o "discernimento e o senso de objetividade" (Vaz, 2002). Nessa categoria, metade $(57 \%)$ das crianças e jovens com SD apresentou detalhes comuns que representavam os aspectos do cotidiano. No tocante aos detalhes incomuns (Dd), estes constituem a capacidade da pessoa de analisar e observar as coisas com mais atenção, cuidado e interesse, verificando se a pessoa é meticulosa e cuidadosa. O índice de respostas dessa categoria, em relação à anterior, aumentou em 17,4\%. Em relação ao detalhe raro (dr), o qual representa as respostas que não são frequentes, foi apresentado um índice de 54,2\%. Os detalhes internos (di) correspondem às intenções introspectivas do indivíduo, e seu percentual foi de 15,7\%. Em se tratando do detalhe externo ou de borda (de), apenas um indivíduo com SD apresentou duas respostas nessa localização.
Os determinantes são categorias que constituem um foco de análise diagnóstica tanto no Zulliger como no Rorschach, em que, provavelmente, a pessoa expressa os traços da sua personalidade (Vaz, 2002). Houve destaque apenas no determinante M- em relação a manifestação na idade. Os determinantes de movimento humano (M) simbolizam a criatividade, espontaneidade e empatia das pessoas. Diante dos resultados desta pesquisa, percebeu-se que não houve respostas de $\mathrm{M}+$, o que indica, segundo Vaz (2002), pessoas ansiosas, tensas, tímidas e de pouca inteligência, etc. Houve ainda pouca expressividade, também, nas respostas referentes a M- e M+-.

Em relação às cores, a cor cromática enfatiza as condições afetivo-emocionais e suas manifestações. Embora os pais e professores tenham considerado as crianças e jovens com SD bastante afetivas, não se observou nas respostas ao Zulliger elementos que indicassem essa afetividade. Apenas duas pessoas deram respostas correspondentes ao FC, que significa relacionamento afetivo adequado. Já para $\mathrm{CF}$, que indica a tendência à excitabilidade emocional, só foi destacada uma resposta. A cor pura (C), que projeta as reações emotivas, foi observada em apenas $11,4 \%$, um equivalente a oito pessoas. A cor nomeada ou numerada foi representada por um indivíduo e sua manifestação pode indicar algum comprometimento de ordem emocional. A cor descrita (Cdesc.) pode indicar dificuldade de ordem intelectual, mas apenas uma pessoa deu resposta para essa categoria. A cor forçada (F-C e C-F) e a cor arbitrária indicaram apenas a expressividade de três sujeitos, podendo significar instabilidade afetiva e relacionamento interpessoal reservado e tímido. As cores acromáticas, por sua vez, sem forma bem-definida (C'F) e com forma bem definida (FC') representam a depressão e sentimentos depressivos. Nesse ponto, apenas três examinados elaboraram respostas relacionadas a esses determinantes.

Os conteúdos demonstram os interesses que as pessoas têm em relação ao mundo a sua volta. No entanto, os conteúdos que se destacaram quanto à faixa etária foram os de natureza abstrata e geográfica, provavelmente decorrentes da experiência escolar.

$\mathrm{Na}$ população pesquisada, percebeu-se que $32,8 \%$ visualizaram figura humana e $12,8 \%$ o detalhe humano que indica uma capacidade adequada de se relacionar com o outro. Em relação ao conteúdo humano descaracterizado $(\mathrm{H})$, foram destacados apenas $11,5 \%$ dos casos e o 
detalhe humano descaracterizado (Hd) foi revelado apenas por duas pessoas. Diante disso, Vaz (2002) comenta que, quando o conteúdo humano possui características de animais ou monstros, pode significar que a relação interpessoal do indivíduo é receosa, cautelosa e controladora. O conteúdo animal (A e Ad) é comum em crianças, mas apresenta tendência a diminuir durante o desenvolvimento. A respeito desse aspecto, $54,3 \%$ das crianças e jovens com SD apresentaram o conteúdo animal e 4,3\% o conteúdo detalhe animal. No conteúdo animal descaracterizado apenas $8,5 \%$ se direcionaram para este e apenas uma pessoa apresentou uma resposta em relação ao detalhe animal descaracterizado.

Diante dos dados do Zulliger, percebe-se que algumas categorias apresentam respostas que caracterizam a deficiência mental. Para Kozma (2007), a deficiência mental faz com que as crianças com SD possuam um aprendizado lento e, por sua vez, demonstram dificuldade no raciocínio complexo e juízo crítico. É importante dizer que, mesmo que elas não consigam destaque no raciocínio complexo, é possível descobrir outras potencialidades que possam desenvolver a sua independência.

Em síntese, as expressões utilizadas pelos pais para descrever o comportamento afetivo dos seus filhos e a forma como estes se relacionam com outras pessoas revelam aspectos positivos e negativos da afetividade. Por outro lado, em relação ao Zulliger, vale acrescentar que o intuito de utilizar essa técnica não foi para simplesmente avaliar as crianças e jovens com SD, mas conhecer, dentro das condições da síndrome, como elas se portariam diante do contexto avaliativo e como poderiam expressar a afetividade. Nesse sentido, mesmo não se obtendo os resultados esperados foi possível coletar dados iniciais de maneira a fundamentar estudos futuros quanto à possibilidade de adaptação da técnica de Zulliger para estes indivíduos (Rodrigues, 2008).

Enfim, em se tratando de um trabalho cujo objetivo era identificar mais que caracterizar os aspectos afetivos, é preciso cautela ao obter uma explicação por esses fatores para a expressão da afetividade na SD. O estudo do desenvolvimento da SD e a expressão de caracterizações da personalidade e comportamentos pode ser uma nova maneira de abordar. Por fim, verifica-se que foi possível analisar e caracterizar, com o apoio da percepção dos pais e dos professores, as manifestações da afetividade das crianças e jovens com SD, sem que, no entanto, fosse possível relacioná-los no plano da técnica de Zulliger. Como último ponto, seria importante dizer que a análise do mundo emocional e/ou afetivo de indivíduos com SD constitui um esforço fundamental para a psicologia contemporânea.

\section{Referências}

Alchieri, J. C., Aquino, J. H. F., Martins, R. R. Oliveira, Z. C. T. de \& Gonçalves, D. M. (2006) Elaboração de normas preliminares para a técnica de Zulliger na Região Nordeste do Brasil. Em N. A. e S. Neto \& D. M. do Amparo (orgs.). Métodos projetivos: Instrumentos atuais para investigação psicológica e da cultura. VI Congresso Nacional da Associação Brasileira de Rorschach e Métodos Projetivos. (pp. 76-85). Brasília-DF: ASBRo.

Bissoto, M. L. (2005). Desenvolvimento cognitivo e o processo de aprendizagem do portador de síndrome de Down: revendo concepções e perspectivas educacionais. Ciências \& Cognição, 04, 80-88.

Coutinho, M. da P. de L. (2005). Depressão infantil e representação social. João Pessoa: Editora Universitária/UFPB.

Doron, R. \& Parot, F. (2001). Dicionário de Psicologia. (1 ${ }^{\mathrm{a}}$ ed.). Lisboa: Climepsi.

Kozma, C. (2007). O que é síndrome de Down. Em Stray-Gundersen, K. (Org.). Crianças com sindrome de Down: guia para pais e educadores (pp. 14-42). Porto Alegre: Artmed.

Lamônica, D. A. C., Vitto, L. P. M. de, Garcia, F. C. \& Campos, L. C. (2005). Avaliação do processo receptivo: investigação do desenvolvimento semântico em indivíduos com síndrome de Down. Revista Brasileira de Educação Especial, 11(01), 81-96.

Marconi, M. de A. \& Lakatos, E. M. (2003). Fundamentos de metodologia científica. ( $5^{\mathrm{a}}$ ed.). São Paulo: Atlas.

Martins, L. de A. R. (2002). A inclusão escolar do portador da síndrome de Down: o que pensam os educadores? Natal-RN: Editora da UFRN.

McConnaughey, F. \& Quinn, P. O. (2007). O desenvolvimento da criança com síndrome de Down. Em K. Stray-Gundersen (Org.). Crianças com syndrome de Down: guia para pais e educadores. (pp. 134-158). Porto Alegre: Artmed. 
Pawlowski, J., Bandeira, D. R. \& Severo, C. T. (2004). Lidando com a falta de instrumentos na avaliação psicológica de um portador de Síndrome de Down. Em C. E. Vaz \& R. L. Gicieff (Orgs.). Congresso Nacional da Sociedade Brasileira de Rorschach e outros métodos projetivos (pp. 233-237). Porto Alegre: SBRO.

Pinto, F. E. M. (2004) O "mundo do coração": os (novos) rumos de estudo da afetividade na Psicologia. Revista Ciências.Humanas, 10 (2), 111-114.

Rodrigues, E. C. (2008). Avaliação das características de afetividade em crianças e jovens com Sindrome de Down. Dissertação de Mestrado. Natal: Universidade Federal do Rio Grande do Norte.

Rodríguez, E. R. (2004). Programa de educación emocional para niños y jóvenes com síndrome de Down. Revista Sindrome de Down, 21, 84-93.

Schwartzman, J. S. (2003). Sindrome de Down. (2 ed.). São Paulo: Memnon.
Silva, N. L. P. \& Dessen, M. A. (2006). Famílias de crianças com síndrome de Down: sentimentos, modos de vida e estresse parental. Interação em Psicologia, 10, 183-194.

Vaz, C. E. (2000). A técnica do Zulliger no processo de avaliação da personalidade. Em J. A. Cunha (Org.). Psicodiagnóstico-V (5 ${ }^{\mathrm{a}}$ ed., pp. 386-398). Porto Alegre: Artmed.

Vaz, C. E. (2002). Z-Teste: Técnica de Zulliger: forma coletiva. São Paulo: Casa do psicólogo.

Ying L., E. P., Ming L., Y., Yan L., N. C. \& Kwan L., V. W. (2006). Successful experience of people with Down syndrome. Jounal of Intellectual Disabilities, 10(2), 143-154.

Recebido em junho de 2008

Reformulado em dezembro de 2008 Aprovado em fevereiro de 2009

Sobre os autores:

Elaine Custódio Rodrigues é psicóloga clínica (CRP13/3597), especialista em Neuropsicologia pela UNIPÊ e mestre em Psicologia pela Universidade Federal do Rio Grande do Norte. É conselheira suplente do Conselho Regional de Psicologia e preside a Comissão de Avaliação Psicológica em João Pessoa-PB, assim como é coordenadora do escritório de representação (CRP/13) de Campina Grande-PB. Atualmente leciona na Especialização em Psicopedagogia das Faculdades Integradas de Patos.

João Carlos Alchieri é professor adjunto da Universidade Federal do Rio Grande do Norte junto aos Programas de Pós-Graduação em Psicologia e Ciências da Saúde. Sua área de atuação é Avaliação Psicológica com ênfase em instrumentos psicológicos, ensino de avaliação psicológica, avaliação de personalidade, saúde e informatização de medidas e instrumentos. Atualmente é coordenador do GT Avaliação de Programas na ANPPEP e bolsista de produtividade. 